\title{
Decoding the Entrepreneurial Capacity: the Case of Entrepreneurial Alertness
}

\author{
Marina Stanić
}

Abstract: Over the last few decades, entrepreneurial alertness has established its place as one of the central concepts in entrepreneurship research. It implies one's ability to identify opportunities that are overlooked by others and as such plays an important role in the process of opportunity discovery and creation. Entrepreneurial alertness is theoretically set as a multidimensional construct that comprises of scanning and searching for new information, associating and connecting seemingly unrelated pieces of information and making evaluations and judgments about potential opportunities. The purpose of this study is to explore the notion of entrepreneurial alertness among the youth in order to identify its relationship with metacognitive knowledge, metacognitive experience, perception of self-efficacy and entrepreneurial intention. The aim is to provide suggestions and guidelines to scholars and educators about the ways entrepreneurial alertness can be developed and enhanced through teaching methods as well as specific activities offered to students during their university study. The sample includes 206 business students on the undergraduate and graduate level majoring in seven different areas (financial management, marketing, general management, trade and logistics, business informatics, entrepreneurship and economic policy and regional development). Statistical methods applied in the data analysis included correlation analysis, factor analysis and analysis of variance (ANOVA). The results showed a statistically significant positive relationship between entrepreneurial alertness and all four preselected variables: metacognitive knowledge, metacognitive experience, perceived self-efficacy, and entrepreneurial intent. Various student activities outside the classroom contribute to higher levels of students' entrepreneurial alertness. However, not all activities equally contributed to the development of students' metacognitive knowledge. Students who volunteered in local non-profit organizations, did an internship in a company that operates in Croatia, participated in providing consulting services to small and medium businesses and took part in national case study competitions demonstrated higher levels of metacognitive knowledge. Finally, the paper provides suggestions to scholars, educators and policy makers in the field of entrepreneurship and education.

Keywords: Self-efficacy; metacognitive knowledge; metacognitive experience; entrepreneurial intention; higher education

JEL Classification: L26, D91, I23

\footnotetext{
* Marina Stanić is at J.J. Strossmayer University of Osijek, Faculty of Economics, Trg Lj. Gaja 7, Osijek, email: marina.stanic@efos.hr
} 


\section{Introduction}

Entrepreneurial alertness is a concept originally developed by Kirzner (1979) as an individual's ability to identify opportunities that are overlooked by others. In the context of entrepreneurship research, alertness has found its place in studies focused on opportunity discovery and opportunity creation. The underlying assumption is that entrepreneurs tend to be more alert to opportunities for developing new entrepreneurial ventures. In line with that, alertness has the potential to contribute to the understanding of how new entrepreneurial opportunities get initiated and pursued. Even though this is theoretically sound, scholars were reluctant to include this concept in their studies due to an ambiguous understanding of the term (Gaglio \& Katz, 2001). Only after the paper written by Tang, Kacmar \& Busenitz (2012), the notion of entrepreneurial alertness was clearly defined and the measurement scale was provided for prospective studies on this topic. According to the authors, entrepreneurial alertness consists of three distinct elements: scanning and searching for information, connecting previously disparate information, and making evaluations on the existence of profitable business opportunities.

With a measurement scale for entrepreneurial alertness at hand, scholars have pursued several research streams by looking for antecedents of entrepreneurial alertness, identifying differences between entrepreneurs and managers, and exploring the nuances of the phenomenon. After being awarded with the International Award for Entrepreneurship and Small Business Research for his work on entrepreneurship and alertness, Kirzner $(2008$, p. 1) stated "This prize, I understood, was thus part of a broad research initiative that might lead to public policies and educational programs that would in turn stimulate and encourage the entrepreneurial potential latent in society, and thus bring about the desirable economic results that successful entrepreneurship can generate". In the spirit of his directive and the general quest for a practical implication of scientific research, this paper sets its goals as follows.

The aim of the paper is threefold: 1) to increase our understanding of the concept of entrepreneurial alertness among young people (students), 2) to analyze its relations to constructs and measures used to predict an entrepreneurial career and 3) to explore ways of enhancing entrepreneurial alertness through activities available to students during their formal education.

\section{Theoretical Framework}

\section{Development of Research in Entrepreneurial Alertness}

The seminal work on entrepreneurial alertness was conducted by Kirzner (1979) who sees an entrepreneur as "one who snuffs out given profit opportunities by promptly 
exploiting them". Critics of Kirzner's theory describe an entrepreneur as relatively passive individual who is alert to exploiting arbitrage opportunities on the market and juxtapose Kirzner's perspective to Schumpeterian view of the entrepreneur as one who is a bold and creative disruptor on the market. However, Kirzner (2008) himself and later studies on entrepreneurial alertness discouraged such views by highlighting the fact that alertness implies a certain proactive approach based on a number of social, cognitive and information processing capacities. The sum of those capacities was later described as 'schemata' - a specific set of mental frameworks that can be utilized to make sense of the world (Valliere, 2013). According to this study, schemata applied by alert individuals is different from schemata used by less alert people in the following ways. Their schemata are richer in value-creation attributes, they are more strongly associated with internal and external stimuli, and they are intentionally primed for activation in response to even very slight stimuli. Another important implication of Valliere's study is that "entrepreneurially alert" set of schemata can be taught and enhanced by specific pedagogical methods that rely on the repetitive analysis of subtle or diverse cases.

While many studies confirmed the uniqueness of alertness as a mental framework, the "entrepreneurial" portion of this concept had to be empirically tested as well. In that context, Kaish and Gilad (1991) explored the differences in the way entrepreneurs, as opposed to managers, expose themselves to information as well as use and evaluate that information. The study reinforced the notion of alertness as a major determinant of entrepreneurship and a special talent that is not equally shared by all. According to their results, new venture founders were willing to undertake a significantly larger volume of information search (using unconventional sources of information), especially those founders with less professional experience. However, the question of differences in mental processes that convert the data into opportunities has remained open. To fill this gap, Gaglio and Taub (1992) examined the notion of entrepreneurial alertness as a set of unique cognitive skills and strategies, and tested it on a sample of business owners and corporate managers. Study participants were presented with an ambiguous business situation and asked to search for new business opportunities or ideas. The analysis found that the two groups appeared to approach the task differently. Finally, it is not just that other people perceive entrepreneurs as highly alert individuals, but the entrepreneurs identify themselves as the ones having a special alertness to opportunity (Hills, 1995).

Once entrepreneurial alertness was established as one of the central notions in entrepreneurship research, scholars moved on to identify determinants of entrepreneurial alertness. Ardichvili, Cardozo \& Ray (2003) applied a systematic approach to theory building utilizing Dubin's theory building framework in the context of the opportunity identification process. Their study resulted in several important findings. First, they confirmed a positive relationship between a high level of entrepreneurial alertness and successful opportunity recognition and development. Second, 
successful opportunity identification is associated with the existence and use of an extended social network. Third, high levels of entrepreneurial alertness are related to high levels of entrepreneurial creativity and optimism (based on high self-efficacy). Finally, the process of opportunity identification results in enriching the entrepreneur's knowledge base and an increase in alertness, leading to the identification of future business opportunities. Thus, the greater the number of previously successful opportunity identification events, the higher the probability of future successful opportunity identification events. In the context of predicting entrepreneurial alertness, entrepreneur's personality traits, social networks and prior knowledge were identified as antecedents of entrepreneurial alertness.

\section{Theoretical Framework and Hypothesis Development}

As a complex construct, that incorporates both cognitive and behavioral elements, entrepreneurial alertness is assumed to be correlated with certain personality traits and entrepreneurial attention. The focus of this study is on the elements that can be influenced by formal education. The following constructs are included in the study.

Entrepreneurial self-efficacy. According to Bandura (2006), self-efficacy refers to an individual's belief in their capabilities to produce given attainments. It is an important element of personal development and change, and it can be learned. Bandura (1990) states that through repeated tasks and successes an individual can gradually build expertise in a particular field (as long as those tasks are complex and challenging enough). Moreover, beliefs about self-efficacy influence the selection of challenges to solve and the amount of effort and time invested in solving the challenges (Miljković Krečar, 2013). An experimental study showed that subjects who are led to believe that they are very competent at decision making see more opportunities and take more risks (Krueger \& Dickson, 1994). This leads to the first hypothesis.

H1: There is a statistically significant positive relationship between self-efficacy and entrepreneurial alertness.

Metacognitive ability. Metacognition represents the control that individuals have over their own learning and cognitions, as a function of a differing ability (between individuals) to be self-reflective and consider alternative cognitive strategies in light of a changing environment (Haynie et al., 2012). Prior empirical studies have shown that prior knowledge is related to the discovery of opportunities (Ucbasaran,Wright, $\&$ Westhead, 2008) and that individuals with no prior business ownership experience detect fewer entrepreneurial opportunities (Baron, 2006). According to Haynie et al. (2012), metacognition represents a variable that can help explain the assimilation of new information into new knowledge, and extend our understanding of the cognitive 
factors that influence entrepreneurial decision making. Research design of this study includes two measures of metacognition - metacognitive knowledge and metacognitive experience. In line with previous research, the second and the third hypothesis go as follows.

$\mathrm{H} 2$ : There is a statistically significant positive relationship between metacognitive knowledge and entrepreneurial alertness.

H3: There is a statistically significant positive relationship between metacognitive experience and entrepreneurial alertness.

Entrepreneurial intention. Valliere (2013) has developed a theoretical model consisting of three factors that influence entrepreneurial alertness. First, through experience, education and prior knowledge, the entrepreneur develops a set of schemata rich in value-creation possibilities. Then, through practice and repeated use, these schemata become highly associated with some domain of stimuli. Finally, the formation of an entrepreneurial intent serves as a trigger for activating a set of schemata that ultimately results in heightened entrepreneurial alertness. Based on this model, the final hypothesis is set as follows.

H4: There is a statistically significant positive relationship between entrepreneurial intention and entrepreneurial alertness.

\section{Methodology and Results}

\section{Sample and Data Collection}

In line with many studies on entrepreneurial intention and entrepreneurial awareness, this study utilizes graduate students as prospective entrepreneurs. The sample is composed of final-year undergraduate students, first- and second-year graduate students majoring in one of seven following areas: financial management $(27.7 \%$ of the sample), marketing (9.7\%), general management (8.7\%), trade and logistics (10.2\%), business informatics (15.0\%), entrepreneurship (16.0\%) and economic policy and regional development $(12.6 \%)$. Business students are typical respondents in this area of study for several reasons. Presumably, they have knowledge and skills (gained throughout their university education) necessary for starting and running a business. Furthermore, they tend to identify themselves with their future career choice (which makes them feel pulled toward it, rather than being pushed into it). Finally, the fact that they will soon complete their formal education may serve as a triggering effect to speed up the decision of pursuing an entrepreneurial career.

Data collection method included self-report written questionnaires that were distributed to students in the classroom. The sample included 206 students with the av- 
erage participant age equal to 23.5 years (standard deviation of 2.28) and respondents being predominantly female (66.5\% of the sample were female students). Majority of respondents ( $84 \%$ of the sample) reported to having work experience (mainly typical part-time student jobs arranged by student service center) and $43.7 \%$ of them have one or both parents with the experience of being an entrepreneur (small and medium-sized enterprise owner).

\section{Measures}

Entrepreneurial alertness is set as the central construct of this study and is measured with a thirteen-item measurement construct adapted from Tang, Kacmar \& Busenitz (2012). Each item of the construct was scored on a seven-point Likert scale (from "Strongly disagree" to "Strongly agree"). According to Cronbach's Alpha values, all subscales have very good internal consistency reliability (Table 1).

Table 1: Measurement construct for entrepreneurial alertness (adopted from Tang, Kacmar and Busenitz, 2012)

\begin{tabular}{|l|}
\hline Item \\
\hline Scanning and search (Cronbach's Alpha $=0.845$ ) \\
\hline 1. I have frequent interactions with others to acquire new information. \\
\hline 2. I always keep an eye out for new business ideas when looking for information. \\
\hline 3. I read news, magazines, or trade publications regularly to acquire new information. \\
\hline 4. I browse the Internet every day. \\
\hline 5. I am an avid information seeker. \\
\hline 6. I am always actively looking for new information. \\
\hline Association and connection (Cronbach's Alpha $=0.858$ ) \\
\hline 7. I see links between seemingly unrelated pieces of information. \\
\hline 8. I am good at "connecting dots". \\
\hline 9. I often see connections between previously unconnected domains of information. \\
\hline Evaluation and judgment (Cronbach's Alpha $=0.880)$ \\
\hline 10. I have a gut feeling for potential opportunities. \\
\hline 11. I can distinguish between profitable opportunities and not-so-profitable opportunities. \\
\hline 12. I have a knack for telling high-value opportunities apart from low-value opportunities. \\
\hline 13. When facing multiple opportunities, I am able to select the good ones. \\
\hline
\end{tabular}

Source: Tang, Kacmar \& Busenitz, 2012

Previous research on entrepreneurial behavior and career choice pointed to several variables relevant for this study. They are entrepreneurial intent, perceived self-efficacy, metacognitive knowledge, metacognitive experience and the amount and types of activities that student had participated in during their university study.

Entrepreneurial intention was measured using a measurement construct adapted from Liñán and Chen (2009) with a five-point Likert scale and five items included. 
An example item is "I will make every effort to start and run my own firm". Cronbach's alpha of 0.946 for this scale points to a very adequate reliability level.

Perceived self-efficacy was assessed using an average of the respondents' answers to the 15 items. The respondents were asked to express the degree of certainty to perform the described task on the scale from one to five with ' 1 ' indicating they are completely unsure and ' 5 ' indicating they are completely sure of their ability. The measurement construct consists of five subscales covering groups of manager's activities related to marketing, innovations, management, risk taking and financial control. An example item is "Define organizational roles, responsibilities, and policies". Cronbach's alpha for this scale is 0.935 .

Metacognitive knowledge and metacognitive experience were assessed using the scales taken from Haynie \& Shepard (2009) with a five-point Likert-type question format. Similar to previous variables, the final score for each of the measurement constructs is the average of the scores on the items included in the construct. Metacognitive experience scale included eight items (Cronbach's alpha $=0.860)$ with one of them being "I challenge my own assumptions about a task before I begin". Metacognitive knowledge scale consists of eleven items (Cronbach's alpha $=0.860)$ and the statement "I think about what I really need to accomplish before I begin a task" was one of them.

In addition to these measures, the questionnaire also included questions about activities that were offered to students during their undergraduate and graduate study. Those activities included student mobility Erasmus+ activities (studying abroad or doing an internship outside Croatia), volunteering activities, doing an internship in local or national companies, participating in consulting work of Legal-Economic Clinic, national case study competitions or various educational projects that provided opportunities for students to travel and visit universities from Europe and the United States of America. All the selected activities provided opportunities for students to gain new knowledge and skills, increase self-awareness, network with national and international companies, and indirectly increase their entrepreneurial awareness.

\section{Analyses and Results}

The first step of the analysis was to assess the relationships among the main variables to test the hypothesis. The analysis included one additional variable that describes student involvement in various activities and projects during the period of university study. Students were able to select among ten different activities and projects. The variable was calculated by counting the number of activities selected by a respondent.

The results for Pearson correlation are presented in table 2. Entrepreneurial alertness has the strongest positive relation with metacognitive experience. Relationship of medium strength was found between entrepreneurial alertness and three other variables: self-efficacy, metacognitive knowledge and entrepreneurial intention. The results shown in table 2 confirm all four hypotheses. 
Table 2: Correlation matrix

\begin{tabular}{|l|c|c|c|c|c|c|}
\hline & 1 & 2 & 3 & 4 & 5 & 6 \\
\hline (1) Entrepreneurial alertness & 1 & $.457^{* * *}$ & $.513^{* *}$ & $.427^{* *}$ & $.313^{* *}$ & .117 \\
\hline (2) Self-efficacy & & 1 & $.517^{* *}$ & $.490^{* *}$ & $.333^{* *}$ & $.157^{*}$ \\
\hline (3) Metacognitive experience & & & 1 & $.783^{* *}$ & $.140^{*}$ & $.312^{* *}$ \\
\hline (4) Metacognitive knowledge & & & & 1 & .117 & $.289^{* *}$ \\
\hline (5) Entrepreneurial intention & & & & & 1 & -.021 \\
\hline (6) Activities total & & & & & & 1 \\
\hline Number of items & 13 & 15 & 8 & 11 & 5 & \\
\hline Cronbach's Alpha & 0.925 & 0.935 & 0.860 & 0.881 & 0.946 & \\
\hline ** Correlation is significant at the 0.01 level. \\
\hline * Correlation is significant at the 0.05 level.
\end{tabular}

Source: Author

Surprisingly, the analysis did not identify a significant relationship between entrepreneurial alertness and amount of activities students participated in during their university study. Theoretically, it makes a sound assumption that participation in various activities and projects exposes students to more information, expands their networks and allows them to develop their skills and knowledge, which can all ultimately lead to higher entrepreneurial alertness. Moreover, number of activities that students participated in is positively correlated with their perception of self-efficacy, metacognitive experience and metacognitive knowledge. To shed more light to this matter, a factor analysis of various types of student involvement was conducted. The results are shown in table 3.

Table 3: Factor analysis of various student activities

\begin{tabular}{|l|c|c|c|}
\hline & \multicolumn{3}{|c|}{ Component } \\
\hline & 1 & 2 & 3 \\
\hline National case study competition & .692 & & \\
\hline Video pitch competition & .683 & & \\
\hline Internship & .630 & & .502 \\
\hline Volunteering & .552 & & \\
\hline Legal-Economic Clinic & .530 & .787 & .723 \\
\hline International case study competition & & .698 & \\
\hline INTENSE project & & .503 & \\
\hline Erasmus+ internship program & & & .789 \\
\hline Erasmus Student Network & & \\
\hline Erasmus+ study program & & \\
\hline Extraction Method: Principal Component Analysis. & & \\
\hline Rotation Method: Varimax with Kaiser Normalization
\end{tabular}

Source: Author 
The goal of a factor analysis was to summarize the activities using a smaller number of components. The analysis singled out three factors. The first factor includes five sets of activities and projects that are organized on a local and national level, and that provide students with the insights into business challenges that profit and nonprofit companies in Croatia face. Besides, participation in those activities helped students to expand their network on a local and national level. The second factor consists of four sets of activities that provide students with the opportunity to get insights into international business practices and connect with the people from abroad. All the activities within the second factor included traveling abroad. Finally, the third factor incorporated only one set of activities and that is studying at Erasmus+ partnership universities for one or two semesters. This activity is focused on gaining new knowledge and skills as well as getting experience of living in a foreign country for a longer period.

Based on the results of factor analysis, a new variable was created that grouped students according to the type of activity they were involved in. The first group matched the first factor, the second group included the second and the third factor (as they both have the international perspective), and the third group involved students who did not participate in activities and projects during their study. Analysis of variance (oneway ANOVA) was conducted to detect any differences in entrepreneurial alertness, self-efficacy, metacognition and entrepreneurial intention among the predetermined groups of students. The analysis yielded the following information. First, students who actively participated in the project, both national and international (group 1 and group 2), demonstrated significantly higher levels of entrepreneurial alertness than students who were passive in that regard $\left(\mathrm{F}_{2,137}=3.400, \mathrm{p}<0,05\right)$. Second, students who were engaged in local and national projects, who were interns in local and national companies and who volunteered in predominantly nonprofit oriented organization (group 1) had significantly higher levels of metacognitive knowledge than students without such experience $\left(\mathrm{F}_{2,137}=5.096, \mathrm{p}<0,01\right)$. Third, students from the group 1 also had significantly higher GPA than the other two groups (group 2 and 3) on both undergraduate $\left(\mathrm{F}_{2,137}=6.169, \mathrm{p}<0,01\right)$ and graduate level $\left(\mathrm{F}_{2,130}=22.272, \mathrm{p}<0,01\right)$.

\section{Discussion and Conclusion}

In line with the suggestion from previous studies (Yu, 2001; Valliere, 2013), the aim of this study were to increase our understanding of the notion of entrepreneurial alertness and its relations to selected concepts from entrepreneurial research on opportunity discovery and cognition. Variables in focus are metacognitive knowledge and metacognitive experience, perceived self-efficacy and entrepreneurial intention. The results of correlation analysis showed statistically significant positive relationship between entrepreneurial alertness and all four variables. Several important implications 
can be drawn from this. First, metacognition and perceived self-efficacy are cognitive and psychological aspects of an individual that have a potential to influence levels of entrepreneurial alertness among the youth population. Moreover, previous studies showed that these aspects could be developed and influenced during formal university education. Metacognitive knowledge includes several dimensions of knowledge such as strategic knowledge (knowledge of general strategies for learning, thinking and problem solving), knowledge about cognitive tasks (knowledge of the condition under which these strategies might be used) and self-knowledge (knowledge of one's strengths and weaknesses). Metacognitive experience is a multidimensional construct that implies a certain level of awareness that connects the present with the past learning experiences and facilitates or inhibits self-regulation of learning in the present as well as in the future. Both metacognitive knowledge and metacognitive experience are positively related to student learning (Pintrich, 2002; Efklides, 2009). Therefore, introduction of teaching methods that are explicitly position for developing metacognitive knowledge and experience could boost entrepreneurial capacity of students. Second, positive relationship between entrepreneurial alertness and entrepreneurial intention suggests that alertness may play an important role in decisions related to career choice. The results of this study serve as a trigger for future research aimed at detecting the nature and direction of this relationship. Third, the results showed that entrepreneurial alertness is closely related to student's perception of self-efficacy. As previous studies showed, perceived self-efficacy plays an important role in the formation of entrepreneurial intention and individual's decision to work for someone or pursue a career of a self-employed person (Feldt \& Woelfel, 2009). Entrepreneurial alertness has a potential to indirectly influence and lead one's decision to an entrepreneurial career.

Furthermore, this study set to explore the ways of enhancing entrepreneurial alertness through activities available to students during their formal education. Results show that, outside the classroom, student's alertness can be increased through various activities that put students outside their comfort zone. Students with higher levels of entrepreneurial alertness were the ones that were involved in the activities that provided them a chance to work on new and complex tasks, participate in the multidisciplinary and multinational teams, expand their network locally, nationally and internationally, operate under uncertainty and work on real-life business problems. However, not all activities equally contributed to development of students' metacognitive knowledge. Students that were predominantly active in projects and tasks closely related to the local and national business environment were the ones with the higher levels of metacognitive knowledge. Those activities included doing internships in companies that operate in Croatia, volunteering in local nonprofit organizations, participating in national case study competitions and consulting small and medium-business owners and managers as part of Legal-Economic Clinic activities.

This study makes several contributions relevant to scholars in the field of entrepreneurship, psychology and education as well as to business educators and policy 
makers focused on boosting entrepreneurial capacity through education. Suggestions for future research are primarily directed toward further exploration of a role that entrepreneurial alertness may play in the process of career decision making and its relationship to entrepreneurial intent. Additionally, digital competences may play an important role in formation of entrepreneurial alertness and should be explored in more details. A weakness of this research design is that it captures only the nature of relationships among selected variables, but it does not explore the causal relationship. Therefore, future studies should employ experimental design to detect the influence of entrepreneurial alertness on the decision making process. Furthermore, educators and scholars should focus on developing pedagogical methods and tools that trigger alertness and boost metacognition.

\section{REFERENCES}

Ardichvili, A., Cardozo, R., \& Ray, S. (2003). A theory of entrepreneurial opportunity identification and development. Journal of Business Venturing, 18(1), 105-123.

Bandura, A. (1990). Perceived self-efficacy in the exercise of personal agency. Journal of Applied Sport Psychology, 2(2), 128-163

Bandura, A. (2006). Guide for constructing self-efficacy scales. Self-efficacy Beliefs of Adolescents, 5(1), 307-337.

Baron, R. (2006). Opportunity recognition as pattern recognition: How entrepreneurs "connect the dots" to identify new business opportunities. Academy of Management Perspectives, 20(1), 104119.

Efklides, A. (2009). The role of metacognitive experiences in the learning process. Psicothema, 21(1), 76-82.

Feldt, R. C., \& Woelfel, C. (2009). Five-factor personality domains, self-efficacy, career-outcome expectations, and career indecision. College Student Journal, 43(2), 429-438.

Forbes, D. P. (2005). The effects of strategic decision making on entrepreneurial self-efficacy. Entrepreneurship Theory and Practice, 29(5), 599-626.

Gaglio, C. M., \& Taub, R. P. (1992). Entrepreneurs and opportunity recognition. Frontiers of Entrepreneurship Research, 12, 136-147.

Gaglio, C. M., \& Katz, J. A. (2001). The psychological basis of opportunity identification: Entrepreneurial alertness. Small Business Economics, 16(2), 95-111.

Haynie, M., \& Shepherd, D. A. (2009). A measure of adaptive cognition for entrepreneurship research. Entrepreneurship Theory and Practice, 33(3), 695-714. DOI: 10.1111/j.1540-6520.2009.00322.x

Haynie, J. M., Shepherd, D. A., \& Patzelt, H. (2012). Cognitive adaptability and an entrepreneurial task: The role of metacognitive ability and feedback. Entrepreneurship Theory and Practice, 36(2), 237-265.

Hills, G. E. (1995). Opportunity recognition by successful entrepreneurs: A pilot study. Frontiers of Entrepreneurship Research, 15, 105-117.

Kaish, S., \& Gilad, B. (1991). Characteristics of opportunities search of entrepreneurs versus executives: sources, interests, general alertness. Journal of Business Venturing 6(1), 45-61.

Kirzner, I.M., 1979. Perception, Opportunity, and Profit. University of Chicago Press, Chicago.

Kirzner, I. M. (2008). The alert and creative entrepreneur: a clarification. Small Business Economics, 32(2), 145-152. DOI:10.1007/s11187-008-9153-7 
Krueger Jr, N., \& Dickson, P. R. (1994). How believing in ourselves increases risk taking: Perceived self-efficacy and opportunity recognition. Decision sciences, 25(3), 385-400.

Liñán, F., Chen, Y. W. (2009). Development and cross-cultural application of a specific instrument to measure entrepreneurial intentions. Entrepreneurship Theory and Practice, 33(3), 593-617.

Miljković Krečar, I. (2013). Predviđanje poduzetničkog ponašanja u okviru Bandurine teorije samoefikasnosti (Predicting entrepreneurial behavior by Bandura's self-efficacy theory). Doctoral dissertation, University of Zagreb, Faculty of Philosophy

Pintrich, P. R. (2002). The role of metacognitive knowledge in learning, teaching, and assessing. Theory into Practice, 41(4), 219-225.

Storr, V. H., \& John, A. (2015). The determinants of entrepreneurial alertness and the characteristics of successful entrepreneurs. In Culture and Economic Action. Edward Elgar Publishing.

Tang, J., Kacmar, K. M. M. \& Busenitz, L. (2012). Entrepreneurial alertness in the pursuit of new opportunities. Journal of Business Venturing, 27(1), 77-94. DOI: 10.1016/j.jbusvent.2010.07.001

Ucbasaran, D., Wright, M., \& Westhead, P. (2008). Opportunity identification and pursuit: Does an entrepreneur's human capital matter? Small Business Economics, 30, 153-173.

Valliere, D. (2013). Towards a schematic theory of entrepreneurial alertness. Journal of Business Venturing, 28(3), 430-442.

Yu, T. F. L. (2001). Entrepreneurial alertness and discovery. The review of Austrian economic, 14(1), 47-63. 